\title{
The Role of Awake Trans Nasal Esophagoscopy in Diagnosis of GERD in Infants with Laryngomalacia
}

\author{
AYATALLAH R. SHEIKHANY, M.D. and AISHA F. ABD EL-HADY, M.D.
}

The Phoniatric Unit, ENT Department, Faculty of Medicine, Cairo University

\begin{abstract}
Background: Laryngomalacia is the most common congenital anomaly causing stridor in infants.

Aim of Study: Was to evaluate Egyptian infants having laryngomalacia and presenting with feeding difficulties to assess the role of awake trans nasal esophagoscopy in diagnosis of GERD and compare the laryngoscopic and esophagoscopic findings in those with failure to thrive to those without failure to thrive to ascertain if severity of the symptoms in those infants influences the laryngeal picture and the esophageal function.
\end{abstract}

Patients and Methods: The study was conducted on 56 infants at the feeding and swallowing disorders clinic at the Phoniatric Unit, Cairo University Hospitals. They were selected from those who presented with inspiratory stridor and one or more symptoms of feeding difficulties. They were divided into Laryngomalacia cases with FTT and another group of laryngomalacia cases without FTT. History taking, laryngoscopic and awake trans-nasal esophagoscopic assessments were carried out for the two groups.

Results: Revealed that infants with FTT showed significant difference in some symptoms of feeding difficulties than those without FTT. There was non significant difference between the two groups regarding the laryngoscopic and the esophagoscopic findings.

Conclusion: Laryngoscopic findings don't change with the laryngomalacia severity. Laryngomalacia cases with feeding difficulties should be evaluated by both laryngoscopy and awake trans-nasal esophagoscopy.

Key Words: Laryngomalacia-Feeding difficulties - Failure to thrive - Laryngoscopic - Esophagoscopic assessment.

\section{Introduction}

LARYNGOMLACIA is the most common cause of stridor in infants and the most common congenital anomaly of the larynx [1,2]. It affects $50 \%$ to $75 \%$ of infants with stridor $[2,3]$. The stridor is

Correspondence to: Dr. Aisha F. Abd El-Hady, E-Mail: aishafawzy1@yahoo.com typically worse with agitation, crying, feeding, and supine positioning.

Patients with laryngomalacia can have feeding difficulty, failure to thrive, dysphagia, aspiration, apnea, cyanosis, reflux, obstructive sleep apnea, and pulmonary hypertension in severe cases $[4,5]$

The etiology of laryngomalacia is likely to be multifactorial. Anatomic, inflammatory, and neurologic factors are all contributing to the disease process [6,7]. Anatomic factors include abnormal prolapse of laryngeal tissue, associated with tissue redundancy causing supraglottic obstruction [8] The cartilaginous theory suggests that immaturity of the laryngeal cartilage contributes to the obstruction [9]. Gastro esophageal reflux disease (GERD) is intimately associated with laryngomalacia and may play a role in the etiology of the disease $[10,11]$ The neurologic mechanism is best supported by the literature as the principal cause for laryngomalacia, including neuromuscular hypotonia and impaired neuromuscular control [12,13]. Thompson demonstrated that abnormal sensorimotor integrative function and laryngeal tone play an important role in the etiology of laryngomalacia [3]

The diagnosis of laryngomalacia is made with flexible fiberoptic laryngoscopy. Findings include collapse of the supraglottic structures during inspiration, leading to inspiratory stridor and airway obstruction, inspiratory prolapse of the arytenoid cartilages, redundant arytenoid mucosa, shortened aryepiglottic folds, and an "omega"-shaped or tubular epiglottis.

In infants with moderate-to-severe laryngomalacia, complementary gastrointestinal studies may be beneficial in prognosis and management. An esophagogram with small bowel follow-through 
is useful in evaluating reflux and aspiration along with ruling out containment gastrointestinal disorders such as pyloric stenosis. Aspiration during feedings can be evaluated by a videofluoroscopic swallow study or a functional endoscopic swallow study [4]. Twenty-four-hour $\mathrm{pH}$ studies and impedance studies may be useful in determining management strategies for the infant with severe reflux.

One of the alternatives for upper GI endoscopies is trans-nasal esophagoscopy. Although, it is an easy procedure to apply in the office, well tolerated and does not need sedation, it is not widely used by the phoniatrcians in Egypt.

To our knowledge, there is no study investigated the role of trans nasal esophagoscopy as an easy tool administered in the office in evaluating the esophageal structure and function in cases of laryngomalacia manifesting with feeding difficulties. This raised the concern to evaluate its role in this common category of population.

The primary aim of this study was to evaluate Egyptian infants having laryngomalacia and presenting with feeding difficulties to assess the role of awake trans nasal esophagoscopy in diagnosis of GERD and compare the laryngeoscopic and esophageoscopic findings in those with failure to thrive to those without failure to thrive to ascertain if severity of the symptoms in those infants influences the laryngeal picture and the esophageal function.

We proposed the following hypothesis that infants with more severe symptoms of feeding difficulties presenting with failure to thrive will be more likely showing laryngeal and esophageal abnormalities.

\section{Patients and Methods}

The study was conducted on 56 infants seeking medical advice at the feeding and swallowing disorders clinic at the Phoniatric Unit, ENT Department, Cairo University Hospitals. They were selected from those who presented with inspiratory stridor and one or more symptoms of feeding difficulties. A careful interview and history taking were done for demographic data, age, sex, birth weight, current weight, natal and peri-natal history, and thorough analysis of the symptoms regarding onset, course, and duration, relieving and aggravating factors, any associated medical concerns or abnormalities of general status affecting weight gain and chest condition. The infants had no history of any accompanying neurological deficits, chro- mosomal abnormalities or congenital heart disease. Clinical interview aimed at detecting the presence of symptoms of GERD such as dysphagia, poor suckling, vomiting and failure to thrive. According to the feeding difficulties, infants were grouped into infants with pre referral diagnosis of failure to thrive (24 infants) and those without pre referral diagnosis of failure to thrive (32 infants) in the pediatrics outpatient clinic.

Laryngoscopic examination was carried out using flexible nasolaryngoscopy. All the 56 infants received a diagnosis of laryngomalacia by two well trained phoniatricians based on the observed findings. Diagnosis depended on visualization of the larynx during respiration with video recording which was reviewed several times which allowed thorough recording of all the findings which supports diagnosis. Laryngoscopic findings that were present in all infants included:

- Anatomical changes in the larynx.

- Associated anomalies in the airway.

- Signs of gastro-esophageal reflux like posterior laryngeal and posterior pharyngeal wall congestion.

- Omega shaped epiglottis, short thickened aryepiglottic folds, redundant mucosal covering overlying arytenoids, edematous posterior glottis and airway narrowing on inspiration.

Infants were also assessed by the laryngoscopy for the presence of posterior glottis hyperemia, inter-arytenoids pachydermia, widening of postcricoid area and regurge of secretions into hypopharyngeal inlet on straining.

Awake trans nasal esophagoscopic examination was done and the infants were assessed for signs of GERD in the form of presence of abnormality in the hypopharyngeal inlet, upper esophageal mucosal covering, lower esophageal mucosal findings, reflux of the gastric content at the lower esophageal sphincter and incompetent non reactive lower esophageal sphincter.

The infants were scored 1 for each symptom and for each finding in the laryngoscopic and esophagoscopic examination and scored 0 for absence of any symptom/laryngoscopic and esophagoscopic finding. After collecting the data, they were tabulated and statistically analyzed. The study was approved by the ethical committee of the department and was conducted in the period from January to June, 2018. 


\section{Results}

The study was conducted on 56 infants seeking medical advice at the feeding and swallowing disorders clinic at the Phoniatric Unit, ENT Department, Cairo University Hospitals.

Statistical analysis was done using IBM@ SPSS $\odot$ Statistics version 22 (IBM $\odot$ Corp., Armonk, NY, USA). Numerical data were expressed as mean and standard deviation or median and range as appropriate. Qualitative data were expressed as frequency and percentage. Chi-square test or Fisher's exact test was used to examine the relation between qualitative variables. All tests were two-tailed. A $p$-value $<0.05$ was considered significant.

In comparing the group with failure to thrive and those without failure to thrive regarding the presented feeding symptoms, infants with FTT showed significant dysphagia and more suckling symptoms than those without FTT.

In comparing the two groups regarding the laryngoscopic findings, no significant difference between the two groups was found

In comparing the two groups regarding the esophagoscopic findings, it revealed no significant difference between the two groups.

Table (1): Comparison between the group with failure to thrive and those without failure to thrive regarding the presented feeding symptoms.

\begin{tabular}{lccc}
\hline $\begin{array}{l}\text { Esophagoscopic } \\
\text { findings }\end{array}$ & $\begin{array}{c}\text { Laryngom- } \\
\text { alacia with } \\
\text { FTT }\end{array}$ & $\begin{array}{c}\text { Laryngom- } \\
\text { alacia without } \\
\text { FTT }\end{array}$ & Sig. \\
\hline $\begin{array}{l}\text { Abnormal lower } \\
\text { esophagus }\end{array}$ & 15 & 21 & 0.809 \\
$\begin{array}{l}\text { Reflux of gastric } \\
\text { content at the LES }\end{array}$ & 15 & 21 & 0.809 \\
$\begin{array}{l}\text { Incompetent LES } \\
\text { Rnc }\end{array}$ & 9 & 13 & 0.813 \\
\hline
\end{tabular}

LES: Lower esophageal sphincter.

FTT: Failure to thrive

Table (2): Comparison between the group with failure to thrive and those without failure to thrive regarding the laryngoscopic findings.

\begin{tabular}{lccc}
\hline $\begin{array}{l}\text { Feeding } \\
\text { symptoms }\end{array}$ & $\begin{array}{c}\text { Laryngom- } \\
\text { alacia with } \\
\text { FTT }\end{array}$ & $\begin{array}{c}\text { Laryngom- } \\
\text { alacia without } \\
\text { FTT }\end{array}$ & Sig. \\
\hline Dysphagia & 24 & 11 & $<0.001$ \\
Vomiting & 19 & 20 & 0.179 \\
$\begin{array}{l}\text { Noisy breathing } \\
\text { after feeds }\end{array}$ & 22 & 23 & 0.065 \\
Poor suckling & 23 & 12 & $<0.001$ \\
\hline
\end{tabular}

FTT: Failure to thrive.
Table (3): Comparison between group with failure to thrive and those without failure to thrive regarding the esophagoscopic findings.

\begin{tabular}{lccc}
\hline $\begin{array}{l}\text { Laryngoscopic } \\
\text { findngs }\end{array}$ & $\begin{array}{c}\text { Laryngom- } \\
\text { alacia with } \\
\text { FTT }\end{array}$ & $\begin{array}{c}\text { Laryngom- } \\
\text { alacia without } \\
\text { FTT }\end{array}$ & Sig. \\
\hline $\begin{array}{l}\text { Posterior glottis } \\
\text { hyperemia }\end{array}$ & 17 & 25 & 0.533 \\
$\begin{array}{l}\text { Interarytenoid } \\
\text { packydermia }\end{array}$ & 19 & 25 & 0.925 \\
$\begin{array}{l}\text { Widening of Post. } \\
\text { cricoid }\end{array}$ & 21 & 24 & 0.244 \\
$\begin{array}{l}\text { Regurge of secretions } \\
\text { into hypopharyngeal } \\
\text { inlet on straining }\end{array}$ & 18 & 42 & 0.1 \\
\hline
\end{tabular}

FTT: Failure to thrive.

\section{Discussion}

It was not until 1942 that the term 'laryngomalacia' was first used by Jackson and Jackson (Malakia is a Greek word that means morbid softening of part of an organ) [16] in describing the congenital laryngeal obstruction and the supraglottic collapse. Laryngomalacia has a disease spectrum that can be divided into mild, moderate, and severe categories [3].

These categories are not based on the quantity of stridor but rather by the associated feeding and obstructive symptoms. Those with mild disease usually have inconsequential inspiratory stridor. Those with moderate disease usually have stridor with feeding-related symptoms. The signs of severity include; poor weight gain (probably the most contributive element); dyspnea with permanent and severe intercostal or xyphoid retraction; episodes of respiratory distress; obstructive sleep apnea; and episodes of suffocation while feeding or feeding difficulties [9].

56 cases were examined in the current study and presented by airway symptoms and feeding difficulties secondary to laryngomalacia.

All the cases were presenting with feeding difficulties, given that swallowing interrupts breathing, infants with airway compromise or respiratory distress may not be able to safely coordinate sucking, swallowing, and breathing, leading to feeding difficulties such as dysphagia, and aspiration $[\mathbf{1 7 , 1 8 ]}$

Among the cases in the current study, 24 infants $(43 \%)$ had failure to thrive (severe cases) while 32 infants $(57 \%)$ had feeding difficulties without failure to thrive (moderate cases). It is known that infants with moderate laryngomalacia present with 
typical stridor and also, described by their caregivers as fussy and hard to feed. They have frequent feeding-associated symptoms of choking, regurgitation, and cyanosis during feeding. If not recognized and managed, feeding problems can lead to aspiration, weight loss, and laborious feedings.

This is in agreement with the facts that the increased metabolic demand of coordinating eating and breathing against the obstruction can be so severe that it results in weight loss and failure to thrive [19] and that the chronic airway obstruction induces an increase in the infant's energy expenditure, which, combined with feeding disorders, results in poor weight gain [9].

Comparison between the two groups of infants having laryngomalacia (Table 1 ) revealed that laryngomalacia cases with FTT have more significant dysphagia and poor suckling as symptoms of feeding difficulty while they showed noisy breathing after feeds and vomiting comparable to those laryngomalacia cases without FTT. Vomiting could be interpreted by the presence of GERD as will be discussed later in addition it can be interpreted by the assumption that aerophagia during feedings causes gastric distention leading to vagal reflexes followed by postprandial vomiting and regurgitation as explained by Hartl \& Chadha [11]

Laryngomalacia has specific features of stridor. However, clinical diagnosis based on listening to the infant's breathing is not absolutely reliable [20] and must be confirmed by direct visualization of the larynx through flexible laryngoscopy. The positive diagnosis of laryngomalacia requires dynamic examination of the larynx in a conscious infant.

Visualization of more or less complete collapse of the supraglottis concomitant with stridor, during inspiration, which can obstruct visualization of the glottis with short aryepiglottic folds; anterior prolapse of the arytenoid cartilages and posterior prolapse of the epiglottis which can be curled up to form a tubular structure and described as omega shaped confirms the diagnosis of laryngomalacia as in agreement with other studies [21].

The two groups showed signs of GERD in the form of posterior glottis hyperemia, interarytenoid pachydermia, widening of post-cricoid and regurge of secretions into hypopharyngeal inlet on straining; with no significant difference. This goes with several authors who have reported that laryngomalacia is often associated with reflux $[\mathbf{2 2 , 2 3 , 2 4 ]}$ in the form of posterior laryngeal congestion and edema over the arytenoidal mucosa.
All the cases under study are having the same laryngoscopic findings; as mentioned above; although manifesting with two different grades of severity and that indicates that severity does not mainly depend on laryngoscopic finding.

The discrepancy showed between the severity of the symptoms and the appearance in laryngoscopy in the current study indicates the need to perform the investigations of GERD to the whole laryngomalacia cases or at least the categories of moderate and severe cases.

Screening of the esophagus in patients with GERD for associated disease has long been the standard of medical practice before the availability of transnasal esophagoscopy (TNE). Most physicians relied on barium esophagography to screen the esophagus for related disease because it was a relatively non-invasive method and sometimes relied on $\mathrm{pH}$-esophageal manometry [25]

Transnasal esophagoscopy is a relatively new technology that has the additional advantages of allowing esophagoscopy to be performed in the office with the patient seated and not sedated.

All cases under study with and without FFT who underwent transnasal esophagoscopy have esophageal abnormality in the form of abnormal lower esophagus, reflux of gastric content at the LES and incompetent LES with no significant difference (Table 3 ).

The result in the current study did not go with our assumption that with increasing severity of the symptoms, the instrumental signs in both larynx and esophagus will increase as our results revealed the affection of esophagus to the same degree in both moderate and severe laryngomalacia cases. This confirms the need of proper GERD management to all cases of laryngomalacia with feeding difficulties not only for helping moderate cases not to progress into FTT but also because moderate cases have confirmed esophageal abnormality that needs management.

The current study shed light on the importance to use both laryngeoscopy and transnasal esophagoscopy in examining the categories of moderate and severe laryngeomalacia cases manifesting with feeding difficulties that will help confirming signs of GERD in those infants in the office and administer the proper therapeutic guidance.

\section{Conflict of interest:}

No conflict of interest was encountered in the current study. 


\section{References}

1- COTTON R.T. and RICHARDSON M.A.: Congenital laryngeal anomalies. Otolaryngology Clinical North America, Vol. 14: pp. 203-218, 1982.

2- Holinger L.D.: Etiology of stridor in the neonate, infant and child. Annals of Otology, Rhinology and Laryngology, Vol. 89: pp. 397-400, 1980.

3- THOMPSON D.M.: Abnormal sensorimotor integrative function of the larynx in congenital laryngomalacia: A new theory of etiology. Laryngoscope, Vol. 117 (Suppl. 114): pp. 1-33, 2007.

4- RICHTER G.T., WOOTTEN C.T., RUTTER M.J. and THOMPSON D. M.: Impact of supraglottoplasty on aspiration in severe laryngomalacia. Annals of Otology, Rhinology and Laryngology, Vol. 118 (4): pp. 259-266, 2009.

5- THOMPSON D.M.: Larygnomalacia: factors that influence disease severity and outcomes of management. Current Opinion Otolaryngology Head Neck Surgey, Vol. 18: pp. 564-570, 2010.

6- HOLINGER L.D. and KONIOR R.J.: Surgical management of severe laryngomalacia. Laryngoscope, Vol. 99: pp. 136-142, 1989.

7- SENDERS C.W. and NAVARRETE E.G.: Laser supraglottoplasty for laryngomalacia: Are specific anatomical defects more influential than associated anomalies on outcome? International Journal of Pediatric Otorhinolaryngology, Vol. 57: pp. 235-244, 2001.

8- SUTHERLAND G.A. and LACK H.L.: Congenital laryngeal obstruction. Lancet. Vol. 2: pp. 653-655, 1897.

9- LANE R.W., WEIDER D.J., STEINEM C. and MARINPADILLA M.: Laryngomalacia: A review and case report of surgical treatment with resolution of pectus excavatum. Arch. Otolaryngology, Vol. 110: pp. 546-551, 1984.

10- GIANNONI C., SULEK M., FRIEDMAN E.M. and DUNCAN N.O.: III Gastroesophageal reflux association with laryngomalacia: A prospective study. International Journal of Pediatric Otorhinolaryngology, Vol. 43: pp. 11-20, 1998.

11- HARTL T.T. and CHADHA N.K.: A systematic review of laryngomalacia and acid reflux. Otolaryngology Head Neck Surgery, Vol. 147: pp. 619-626, 2012.

12- MCSWINEY P.F., CAVANAGH N.P. and LANGUTH P.: Outcome in congenital stridor (laryngomalacia) Arch. Dis. Child, Vol. 52: pp. 215-218, 1977.

13- BELMONT J.R. and GRUNDFAST K.: Congenital laryn- geal stridor (laryngomalacia): ETIological factors and associated disorders. Annals of Otol. Rhinol. Laryngology, Vol. 93: pp. 430-437, 1984.

14- OLNEY D.R., GREINWALD H.J., SMITH R.J. and BAUMAN N.M.: Laryngomalacia and its treatment. Laryngoscope, Vol. 109: pp. 1770-1175, 1999.

15- SHAH U.K. and WETMORE R.F.: Laryngomalacia: A proposed classification form. International Journal of Pediatric Otorhinolaryngology, Vol. 46: pp. 21-26, 1998.

16- LEE K.S., CHEN B.N., YANG C.C. and CHEN Y.C. Laser supraglottoplasty for severe laryngomalacia: A study of symptomatic improvement. International Journal of Pediatric Otorhinolaryngology, Vol. 71: pp. 889-895, 2007.

17- PORTIER F., MARIANOWSKI R. and MORRISSEAUDURAND M.P.: Respiratory obstruction as a sign of brainstem dysfunction in infants with Chiari malformations International Journal of Pediatric Otorhinolaryngology, Vol. 57: pp. 195-202, 2001.

18- PANDORA J.H., DAVID M.A., MARTIN B.C., KEITH L. and AGOSTINO P.: The effect of aryepiglottoplasty for laryngomalacia on gastro-oesophageal reflux. International Journal of Pediatric Otorhinolaryngology, Vol. 67: pp. 11-14, 2003.

19- LANDRY A.M. and THOMPSON D.M.: Review article. laryngomalacia: Disease presentation, spectrum, and management. International Journal of Pediatric Otorhinolaryngeology, 753526, 2012.

20- JACOBS I.N., TEAGUE W.G. and BLAND J.W.: Pulmonary vascular complications of chronic airway obstruction in children. Arch. Otolaryngol. Head Neck Surgery, Vol. 123 (7): pp. 700-704, 1997.

21- ZWARTENKOT J.W., HOEVE H.L. and BORGSTEIN J.: Inter-observer reliability of localization of recorded stridor sounds in children. International Journal of Pediatric Otorhinolaryngology, Vol. 74 (10): pp. 1184-1188, 2010.

22- SMITH G.J. and COOPER D.M.: Laryngomalacia and inspiratory obstruction in later childhood. Arch. Dis. Childhood, Vol. 56: pp. 345-349, 1981.

23- NUSSBAUM E. and MAGGI J.C.: Laryngomalacia in children. Chest, Vol. 98: pp. 942-944, 1990.

24- McCLURG F.L. and EVANS D.A.: Laser laryngoplasty for laryngomalacia Laryngoscope, Vol. 104: pp. 247-252, 1994.

25- OTT D.J., GELFORD D.W. and WU W.C.: Reflux esophagitis: Radiographic and endoscopic correlation. Radiolog, Vol. 130: pp. 583-588, 1979. 


\section{دور منظار المرئ الأنفى أثناء اليقظة في تشخيص الأرتجاع الهُوة

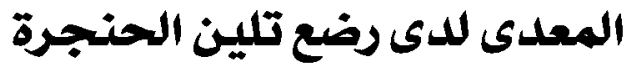

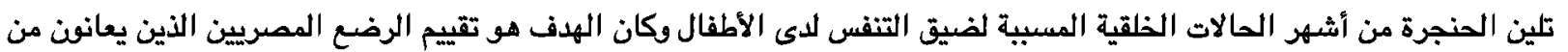

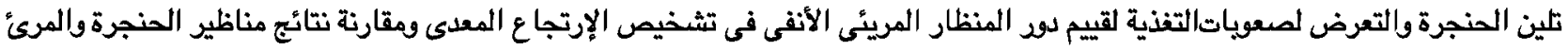

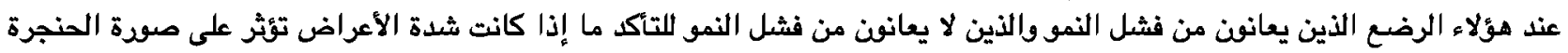
وضظيفة المرىئ.

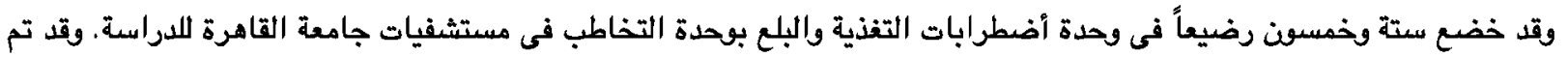

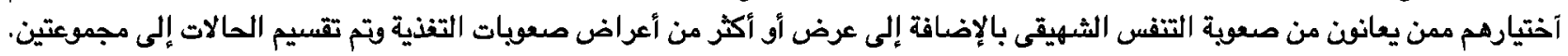

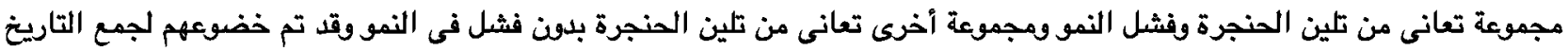

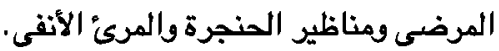

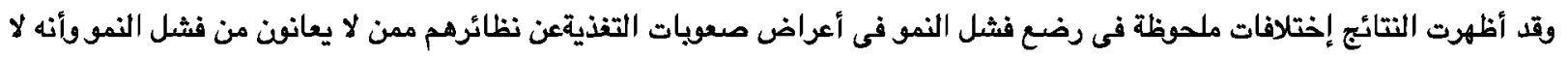

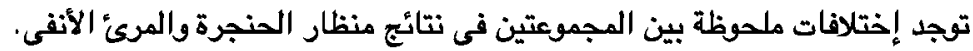

الخلاصة أن نتائج المنظار الحنجرى لا تتغير مع تغير شدة تلين الحنجرة وإنه من الضرودة أن يتم تقييم حالات تلين الحنجرة وصعوبات التفذية بمنظارى الحنجرة والمرىئ الأنفى. 